\title{
'Certified to make a difference': the motivation and perceptions of newly qualified early years teachers in England
}

\author{
Amanda Henshall, Louise Atkins, Rebecca Bolan, Jill Harrison \& Heather \\ Munn
}

To cite this article: Amanda Henshall, Louise Atkins, Rebecca Bolan, Jill Harrison \& Heather Munn (2018): 'Certified to make a difference': the motivation and perceptions of newly qualified early years teachers in England, Journal of Vocational Education \& Training, DOI: 10.1080/13636820.2018.1437063

To link to this article: https://doi.org/10.1080/13636820.2018.1437063

\section{曲 Published online: 01 Mar 2018.}

Submit your article to this journal $\sqsubset$

Џ Article views: 12

Q View related articles $₫$

View Crossmark data $\asymp$ 


\title{
'Certified to make a difference': the motivation and perceptions of newly qualified early years teachers in England
}

\author{
Amanda Henshalla ${ }^{a}$ Louise Atkins ${ }^{b}$, Rebecca Bolan ${ }^{b}$, Jill Harrison ${ }^{b}$ and \\ Heather Munn ${ }^{b}$ \\ aFaculty of Education and Health, Department of Teacher Education, University of Greenwich, London, \\ UK; ${ }^{b}$ Faculty of Education and Health, Department of Education and Community Studies, University of \\ Greenwich, London, UK
}

\begin{abstract}
The last 20 years have brought numerous workforce reforms to the early years sector, enacted in the name of professionalisation, including the recent introduction of a new postgraduate qualification, the Early Years Teacher Status. This article features data from interviews with 22 participants who had just completed this award and situates their views in the relevant policy context and alongside a discussion of what it means to professionalise the early years sector and create a graduate led workforce. The data support findings from similar studies of Early Years Professionals, namely that the interviewees are passionate about working with young children. They view the sector as in need of change, and themselves as potential leaders and agents of change. The participants endorse the view that up-skilling the workforce is essential to the professionalisation of the sector and improving the quality of early years education.
\end{abstract}

\section{ARTICLE HISTORY}

Received 7 April 2017

Accepted 2 January 2018

\section{KEYWORDS}

Early years; EYTS; professionalisation; teacher training

\section{Introduction}

It has become an article of faith for governments across the world that investing in the welfare of young children and developing provision for them is a benefit to the economic well-being of societies (Miller and Cameron 2014; Organisation for Economic Cooperation and Development (OECD) 2012). With rising parental employment and the recognition that building strong foundations in the early years are important for lifelong learning (Campbell-Barr and Leeson 2016) it has become policy in many countries to invest in early years provision as it is seen to bring strong returns in later education.

In 2014, a new qualification was introduced to the early years sector in England, that of Early Years Teacher Status (EYTS). The qualification was launched as part 
of the professionalisation agenda for the early years workforce (Department for Education 2013). At the time of writing, there are four pathways to achieving EYTS offered by the National College for Teaching and Leadership (NCTL), which manages the allocation of teacher training places and awards teacher status. These pathways are delivered via a selected group of university training providers, there are three postgraduate routes and an undergraduate pathway. The postgraduate routes support those from different academic backgrounds who are looking for career change (Graduate mainstream route), those who are already working in settings who hold a degree or equivalent (Graduate entry pathway) and those who want to train directly with a setting in partnership with the university (Schools direct pathway). The undergraduate route allows trainees to complete their EYTS alongside their degree, only gaining the status on the successful completion of their degree (Undergraduate entry pathway).

The predecessor to EYTS was the award of Early Years Professional Status (EYPS), itself introduced relatively recently in 2007. The EYTS programme has been aligned with teacher training for the primary phase and has built on and replaced the EYPS programme. The Department for Education (DfE) claimed that EYTS is equivalent to Qualified Teacher Status (QTS), which is awarded to teachers in primary and secondary after completing a recognised course of teacher training. In order to achieve EYTS, as with EYPs before them, trainees must conform to a series of: 'centrally determined professional standards' (Barron 2016, 327) specifically constructed around working with babies, toddlers and young children.

The introduction of EYTS has not been universally welcomed; Professor Cathy Nutbrown, author of a significant review of early education and childcare qualifications (Nutbrown 2012), wrote of her concerns that the new award may confuse parents and practitioners, in terms of its difference from EYPS, and criticised the decision not to award QTS and consequently parity with other teachers in terms of pay and conditions (Nutbrown 2013).

This article explores the reasons underlying the choice by a cohort of trainees to undertake the EYTS award at a University in the south east of England and their views about the impact they hope to have on the early years sector. We begin by outlining the policy developments that led to the introduction of EYTS, before going on to examine the debates around the professionalisation of the workforce, the drive to recruit graduates and the role of the early years teacher. This offers a framework to illuminate the responses of the research participants.

\section{Policy background}

The last few decades have seen unprecedented levels of change and expansion of provision in the early years sector in England, as in many other developed nations. As Kendall et al. (2012) point out, some commentators view these developments as the straightforward consequence of a rise in the employment of mothers of pre-school age children, from the late 1980s onwards (Cameron, Mooney, and 
Moss 2002) and government aims of raising outcomes for young children and reducing child poverty. Yet other observers have situated these changes within the turn to neoliberal policy-making with its focus on increasing state control over education and 'forming the skills and attitudes needed by a productive workforce' (Connell 2013, 104).

The early years sector in England gained enhanced recognition of its importance in children's lives under Labour governments from 1997 to 2010 (Hallet 2013). The National Childcare Strategy launched in 1998, highlighted the importance of investment in training to 'bring people up' to a national standard (Cameron, Mooney, and Moss 2002, 573). The Green Paper, Every Child Matters (2003) also highlighted the importance of early years workforce reform, and in tandem with The Children's Plan in 2007, pushed for the development of high-quality pedagogical practice and endorsed the view that the more highly trained the practitioner the more positive impact this would have on children's learning and development.

Yet as Urban (2008) points out, the concept of 'quality' is not an unproblematic one, and has been critiqued:'for its implicit relatedness to notions of universality, technocratic manageability and measurability' $(2008,138)$, and such neoliberal constructions of quality are frequently used to legitimate increasing levels of regulation and the reduction of practitioners' autonomy.

The 10-Year Strategy for Childcare (HM Treasury 2004) outlined the staff to children ratios in settings, the minimum level of qualifications for practitioners and pushed to have settings led by graduates (Gourd 2013). In 2007, postgraduate status was introduced by the now defunct Children's Workforce Development Council (CWDC), via the Early Years Professional Status (EYPS) award, designed to recruit graduates and seen as a key strategic role in improving the skills of the workforce (Whalley 2008). The CWDC (2008) envisioned EYPs as change agents and leaders of practice in the early years. This agenda for improving provision through more highly trained staff was given added force through linkage to tackling child poverty and improving the life chances of children from disadvantaged backgrounds.

Contemporaneously, the demand for places in early years settings was fuelled by additional government funding for free places, firstly in 1998, four-year olds became entitled to free part-time places for the three school terms immediately preceding their entry into compulsory education. In 2004, this was extended to include children aged three, and to disadvantaged two-year olds in 2009, following a pilot scheme in 2007 (Gourd 2013).

Although during the years of Labour administration there was an increase in the level of qualifications held by early years practitioners, this was not consistently the case across the whole sector (Faulkner and Coates 2013). The Department for Education (DfE) of the Conservative and Liberal Coalition government commissioned Professor Cathy Nutbrown to conduct a review of childcare qualifications and early education with the view to making recommendations to enhance the sector. Nutbrown (2013) found that there was a plethora of early years qualifications available, in fact around 400 of them, which was confusing for practitioners, 
employers and parents. Nutbrown proposed a new set of consistent job titles and roles culminating with the introduction of Early Years Teacher, a role that she recommended should have Qualified Teacher Status (QTS), in common with teachers in the primary and secondary phases.

In More Great Childcare (DfE 2013), the government set out its response to the Nutbrown Review (2013) and outlined its proposal to build a more professional early years workforce. The DfE claimed to agree that there was a need to transform the status of the workforce and recruit more graduates, however they did not accept Nutbrown's recommendation of awarding QTS to early years teachers.

In her response to More Great Childcare, Nutbrown (2013) reports a misunderstanding amongst the early years workforce that now early years teachers would have QTS, positing that they had perhaps been 'misled' by government. The same misunderstanding occurred when EYPS was introduced (Murray 2009 cited in Simpson 2010). This confusion over status indicates the long-standing desire amongst early years practitioners for parity with their colleagues in primary and secondary schools. Barron (2016) points out that one possible reason for EYPs not being labelled as teachers, was a concession to market forces within the early years sector, where many settings are private businesses that would baulk at meeting the costs of teachers' pay and conditions. By not giving EYTS parity with QTS, the government has perhaps been making a similar concession.

Arguably, Nutbrown's strongest criticism was reserved for the DfE's view that increasing the level of qualifications in the sector meant that staffing ratios could be changed: 'Reducing the number of adults available to work with very young children will dilute any positive effects on the quality of the experiences children could expect to receive' (Nutbrown 2013, 8).

\section{Professionalising the early years workforce}

As mentioned earlier, the introduction of the EYTS award was part of professionalisation agenda for the early years sector in England. The concepts professional and professionalism have been widely debated and are highly contested (Simpson 2010; Brock 2013). Rather than revisiting these debates, this article focuses mainly on the concept of professionalisation, in order to understand the drivers for the introduction of EYTS.

According to Evetts (2014), within the sociology of the professions, professionalisation is generally seen as the progression of an occupational group to the status of a profession, with the concomitant rewards. Simpson (2010) identifies two main strands of thinking about professionalisation in the early years sector. One, from a feminist poststructuralist perspective exemplified by the work of Osgood (2006) sees the workforce reforms engineered by professionalisation as limiting practitioners to a particular'normalised and conformist construction of professionalism' (Osgood 2006, 9) within a technicist discourse of education. Whereas Miller (2008 
cited in Simpson 2010), with reference to EYPs, saw more options available to them to exercise agency in how they are positioned as professionals.

In her discussion of how the use of a discourse of professionalism differs across occupations, Evetts (2014) highlights McClellends work (1990, 170) distinguishing between:'professionalization (sic) 'from within' (that is, successful manipulation of the market by the group e.g. medicine and law) and 'from above' (that is, domination of forces external to the group e.g. engineering and social work)' (2014, 40-41).

In the former case, where moves towards professionalisation come 'from within', then what Evetts calls the 'appeal to professionalism' $(2014,40)$ may work to the advantage of the occupational group in securing status and rewards by utilising the discourse of professionalism: 'in constructing its occupational identity, promoting its image with clients and customers, and bargaining with states to secure and maintain its (sometimes self) regulatory responsibilities' $(2014,41)$.

Conversely when professionalisation is imposed or encouraged 'from above' $(2014,41)$, then the 'appeal to professionalism', including ideals such as autonomy and public service, may be a seductive falsehood or at least selective, in order to attract new professionals, as in reality occupational control is not generally included: 'Rather, the discourse is used to promote and facilitate occupational change (rationalisation) and as a disciplinary mechanism of autonomous subjects exercising appropriate conduct' $(2014,41)$.

As Hammond et al. assert, the agenda of professionalisation within the early years sector 'has been articulated, imposed and regulated from without' (2015, 143) by policy-makers. In addition, Osgood (2006) highlighted concerns that the actual process of professionalisation could facilitate greater government control.

Evans (2008) points out that professionalism has been redefined for various public sector occupations, including teaching. Since the late 1990s, what has been termed New Professionalism (NP) for teachers was constructed via policy documents, particularly under successive Labour governments. Elements of NP include: performance management; professional standards; target setting; and continuing professional development (Storey 2009; Walker et al. 2011).

Some observers, for example, Beck (2008, 2009, cited in Storey 2009) have argued that NP has de-professionalised teachers, by removing autonomy and increasing external scrutiny and state control. Evans writes of the 'shift of power' common to various new professionalisms: 'whoever used to call the shots no longer does so (or, or at least, does so to a lesser extent)' $(2008,21)$.

Yet the early years workforce never had the status, the high levels of pay nor the autonomy enjoyed by other more well established professional groups. It could be argued that New Professionalism may be beneficial to the early years sector, if this results in achieving the status of a profession. However, if recognition as a profession includes financial rewards, the early years sector has been unfortunate in this regard. Pay within the sector remains poor, with early years teachers not receiving the same remuneration as other teachers. Even if a qualified early years teacher works as a reception teacher in a school, s/he may only be paid at the level 
of an unqualified teacher, although this is still higher pay than they would receive working within other parts of the early years sector.

The professionalisation of the early years workforce has frequently been associated with raising the level of qualifications of practitioners (Faulkner and Coates 2013; Peeters and Vandenbroeck 2011; Urban 2010) and since the late 1990s there has been an emphasis on making the early years workforce graduate led (Lloyd and Hallet 2010, 75). The drive to create a more highly qualified workforce derives from a consensus that this leads to better outcomes for children, as will be discussed later in this article.

One possible inference from More Great Childcare (Department for Education 2013) is that the government's motivation to professionalise the early years workforce is partly pecuniary, given this document's view that highly qualified staff should be able to work with larger groups of children. This would reduce staffing costs for settings and presumably the cost of childcare, which in turn would reduce the economic burden on parents and on the state, which currently funds early education and childcare for many children.

Lloyd and Hallet (2010) discusses a qualitative study conducted by Hallet, comprised of focus groups with EYPs on their experiences as professionals. The participants' views on the attributes of the early years professional formed around three main areas: interpersonal skills, leadership, and personal qualities and knowledge. The participants discussed how these areas were constituted, as follows: 'The EYP candidates viewed the following interpersonal skills and qualities as professional attributes:'understanding,',a listener,' 'trustworthy','genuine,',consistent,',believing', 'passionate' and 'a risk taker' (Lloyd and Hallet 2010, 82).

The participants mentioned the following as characteristics of leadership:"'motivational", "to inspire others", "being a role model", "enabling", "charisma", "improves", "progressive", "strategic", "decision maker" and "delegate"' (Lloyd and Hallet 2010, 82).

Similarly, Brock (2013) offers a typology of the dimensions of professional behaviour and practice, drawn from the responses of early years educators in her two phase study. This typology includes:'(1) knowledge, (2) qualifications, training and professional development, (3) skills, (4) autonomy, (5) values (6) ethics and (7) rewards' (Brock 2013, 27). By 'rewards' here, Brock refers to: 'social status, power, salary, sense of vocation and enjoyment of work' $(2013,41)$.

There is obvious overlap between the views of Lloyd and Hallet's (2010) participants and those of Brock's (2013) research in their views of what constitutes an early years professional. These two studies are particularly relevant to our research, as they include participants of graduate level pursuing a qualification designed to embody professionalism within the early years workforce. Both descriptions of the early years professional include the possession of a body of specialist knowledge, which is a commonly held perception of professionalism, particularly in functionalist theories of professionalism. 
This body of specialist knowledge within the role of an early years professional includes:'developmental psychology, how children think and learn, curriculum and play-based pedagogy, individual needs, sociocultural issues and policy development' (Brock 2013, 36). Yet, as Urban (2008) points out, what counts as professional knowledge within early education is hierarchically produced, cascading down from academic research and debate, through training, into practice, where it is expected to be applied by practitioners whose voices were absent from its making.

However, the possession of all these characteristics, knowledge, attributes and skills may count for nought if practitioners are prevented from using them. As Peeters and Vandenbroeck (2011) point out, staff need to be supported in utilising their professional knowledge within their practice. Simpson (2010) reports that some of the EYPS in his research were unable to fully actualise their role; their opportunities for exercising agency were closed down by other staff members in their settings. Davis and Barry (2013) discuss the possibility of resistance to EYPs leadership. Those of their respondents who worked alongside EYPs but were not themselves qualified to that level felt that EYPs may meet with 'resentment or inflexibility' $(2013,41)$. Newly qualified early years teachers may face equal challenges.

This could be described as an example of resistance to EYPS attempts to enact their professionalism. Despite government fiats, as Evans $(2008,27)$ points out:

To be real, professionalism has to be something that people- professionals- actually 'do', not simply something that government or any other agency wants [emphasis in original] them to do, or mistakenly imagines they are doing.

\section{A graduate led workforce}

The drive to increase the level of qualifications of the early years workforce rests on the recognition of the importance of highly qualified staff working with young children. Sylva et al.'s (2004) longitudinal project The Effective Provision of Preschool Education (EPPE) and the connected study, Researching Effective Pedagogy in the Early Years (REPEY) (Siraj-Blatchford et al. 2002) are well known in the sector and have significantly influenced policy. The research reported that:'setting staff with higher qualifications, have higher quality scores and their children make better progress... effective pedagogy included interaction traditionally associated with the term 'teaching' (Sylva et al. 2004, 9).

Furthermore, there was additional support for this by Sylva et al. (2014) in the Effective Pre-school, primary and Secondary Education (EPPSE 3-16) project which reported that attendance at a pre-school had a longer term effect in predication of 5 or more GCSEs at grade $A^{*}-C$ (Sylva et al. 2014).

This chimes with what has been termed 'credentialism' (Collins 1979, 1981, cited in Evetts 2014), that is the process of developing organisational professionalism by training and certification of practitioners. Drawing on the discourse of this 
professionalism may become an effective means of inducing social control and change within an occupation (Evetts 2014).

It is important to note that the level of qualifications of staff does not by itself have a magical, transformative effect on children's outcomes. For settings to have this impact, there would need to be the same quality of education and care seen in the EPPE and REPEY research. The assumption is that highly qualified staff would provide this type of education and care.

The drive to improve the qualification levels of staff has been expected to raise the status of a traditionally less well regarded sector. Historically, the early years workforce, perhaps because of the connotations attached to working with young children, has not been considered to possess high status (Moyles 2001; Hargreaves and Hopper 2006; Brock 2013). This raises the question why ambitious graduates, with other more high status employment options open to them, would choose to work in the early years. Perhaps for many early years practitioners, the emotional rewards and desire to improve children's lives outweigh this lack of status. Unfortunately, these laudable motives could be used against them; government would have little incentive to increase pay and conditions if it could still recruit a dedicated workforce.

Alternatively, the process of professionalisation may form part of the appeal to new recruits. New early years teachers are likely to be aware that the sector is undergoing this process which could improve the status of their occupational group.

Brock's participants also felt that there was a lack of awareness amongst the general public about the specialist knowledge and skills of early years practitioners and:

Several of the participants believed that there was generally a lack of understanding about early childhood education and they wanted their professional knowledge and experience recognized and accorded appropriate status. $(2013,39-40)$

The proliferation of different qualifications and titles within the early years sector seems to have added to the confusion of those outside the field about what constitutes early education, perhaps the proposals to streamline qualifications may make it easier to raise the profile of the profession and facilitate understanding of the field.

The label of 'teacher' arguably carries with it additional status, although according to Fumato, Hargreaves, and Maxwell (2004) there has been some reluctance to apply this label to early years educators, as it connotes a structured, pedagogical role, rather than the concern with children's development that is so essential to early years. However, Fumato, Hargreaves, and Maxwell (2004) go on to argue that all staff who work with young children in early years settings include teaching as part of what they do. They further characterise practice in early years as being predominantly play based and focusing on the needs of the child.

Ofsted (2015) clearly define how they conceptualise teaching in the early years:

Teaching should not be taken to imply a 'top down' or formal way of working. It is a broad term that covers the many different ways in which adults help young children 
learn. It includes their interactions with children during planned and child-initiated play and activities: communicating and modelling language, showing, explaining, demonstrating, exploring ideas, encouraging, questioning, recalling, providing a narrative for what they are doing, facilitating and setting challenges. It takes account of the equipment adults provide and the attention given to the physical environment, as well as the structure and routines of the day that establish expectations. Integral to teaching is how practitioners assess what children know, understand and can do, as well as taking account of their interests and dispositions to learn (characteristics of effective learning), and how practitioners use this information to plan children's next steps in learning and monitor their progress. (2015, 35-36)

This accords with Fumato et al.'s argument (2004) that many interactions between adults and children in settings could be labelled as teaching, and also includes a focus on play and child-centred learning, but it is strongly focused on the transmission of knowledge and skills, assessment and monitoring progress. There is an absence here of the personal qualities and attributes seen as so important by the EYPs mentioned earlier, unless one includes the word 'encouraging' as indicating the disposition of the teacher.

A key difference between the new standards against which EYTs are assessed, compared with the standards used to assess EYPs, is that the latter set had a more holistic approach to education and care, whereas the new standards are more focused on teaching, indeed this was necessary in order to align them with the standards for primary teaching. Thus in terms of policy, a move is occurring towards producing early years teachers with a strong body of professional knowledge, which is handed down from on high, rather than being in possession of particular personal qualities.

Yet, in creating the award of Early Years Teacher, but not giving this award QTS and parity with colleagues in primary and secondary, the government seems to be attempting a sleight of hand, claiming to advance the status of those who work with young children but at the same time, not recognising that their professional knowledge and skills are of the same value as those of other teachers (Gourd 2013).

Leadership is an important part of the role of the new early years teachers, and of early years professionals before them. Both roles carry an expectation of leading practice in settings and also leading for change. Just as the EYPs were expected to be 'change agents' (Lloyd and Hallet 2010; Davis and Barry 2013) the EYTs are also expected to 'build upon the strengths of the Early Years Professional programme' (Department for Education 2013, 7). The implication is that a sector that has experienced massive change over the last 20 years still needs to undergo further transformation, and raises the question, when will the sector be sufficiently professionalised?.

\section{The study-reasons for becoming an early years teacher}

The study explored the reasons and assumptions underlying the participants' decisions to undertake the EYTS award, and how they viewed their future possible 
impact in settings. Semi-structured interviews were conducted with trainees on completion of the programme, in this way it was possible to access all the 20132014 cohort, 22 in total. We thought that participants were likely to have multiple, interconnected reasons for choosing to undertake the EYTS award, so interviews were used as the most effective method to access these data.

The study received ethical approval from the University's Research Ethics Committee and all participants gave consent to take part. All interviews were conducted by a member of the early years teaching team at the university. This meant that a key ethical issue in the project was to avoid the perception that participation may have affected students' assessment, so the interviews were conducted after they had achieved the EYTS award, and each individual one was conducted by a team member who had not taught or assessed that participant. As the programme was a new one, the interview questions were chosen with a mind to understanding the participants' experience of it and how the course could be enhanced. Interview responses were recorded via detailed notes.

Sociodemographic data were collected from all participants at the beginning of the interview, the Tables 1-3 display the sample characteristics:

As can be seen, the participants were mainly female, the majority were less than or equal to 30 years of age. Participants were asked to describe their own ethnic background, which produced the following data, with one participant not declared:

All the data were analysed thematically, using the process described by Braun and Clarke (2006). Initial codes that identified interesting aspects of the data were devised and used by individual members of the team, who then compared their coding to develop a comprehensive coding frame and ensure reliable use of codes. Then team members developed themes inductively from the data, by examining the codes and grouping them. This resulted in 14 themes, which were then explored before being grouped into three overarching or global themes (AttrideStirling 2001).

The next section will explore the findings in detail, focusing in turn on each of the global themes.

Table 1. Participants' Gender.

\begin{tabular}{lcc} 
& \multicolumn{2}{c}{ Age } \\
\cline { 2 - 3 } Gender & $30<=$ years & $31-45$ years \\
\hline Female & 15 & 5 \\
Male & 0 & 2 \\
\hline
\end{tabular}

Table 2. Participants' Ethnicity.

\begin{tabular}{lccccccc}
\hline White British & Black British & White & British & Asian British & Indian & Irish & Pakistani \\
\hline 9 & 3 & 2 & 2 & 2 & 1 & 1 & 1 \\
\hline
\end{tabular}


Table 3. Final themes.

\begin{tabular}{|c|c|c|c|}
\hline \multirow[b]{2}{*}{ Sub-themes } & \multicolumn{3}{|c|}{ Global themes } \\
\hline & (1) The professional self & $\begin{array}{l}\text { (2) Perceptions of the } \\
\text { sector }\end{array}$ & $\begin{array}{l}\text { (3) A field in flux-changes } \\
\text { in early years }\end{array}$ \\
\hline (1) & Wanting to be a teacher & $\begin{array}{l}\text { Accessibility of working in } \\
\text { early years }\end{array}$ & Ambition \\
\hline (2) & $\begin{array}{l}\text { Wanting to work with young } \\
\text { children }\end{array}$ & Benefits of EYTS in the field & Changes needed \\
\hline (3) & $\begin{array}{l}\text { Emotional rewards of work- } \\
\text { ing with children }\end{array}$ & $\begin{array}{l}\text { Distinctiveness of early years } \\
\text { phase }\end{array}$ & Resistance \\
\hline (4) & Leadership & $\begin{array}{l}\text { Low status of early years } \\
\text { sector }\end{array}$ & Agents of change \\
\hline (5) & Professionalism & $\begin{array}{l}\text { Qualifications-graduates vs. } \\
\text { unqualified }\end{array}$ & \\
\hline (6) & Feelings about QTS & & \\
\hline (7) & Previous experience & & \\
\hline
\end{tabular}

\section{Findings}

\section{The professional self}

The participants' motivation for undertaking the EYTS programme had two key dimensions; the desire to work with very young children; and the desire to become a teacher. Many of the interviewees spoke of an inner 'knowing' that they wanted to work with children, particularly in the early years phase. The word 'always' was used frequently, interviewees had 'always wanted to work with children'. All but the two male interviewees had previous experience of working with young children which had informed their decision to take the EYTS award.

Several of those in paid employment in the sector had been encouraged by their managers to enrol for the EYTS award:'School wanted to expand and encouraged me to complete EYTS (as they wanted me to have a teaching qualification) I will now be a reception teacher'.

Working with young children was rewarding and satisfying on an emotional level for many of the interviewees, as in previous research with early years practitioners (Brock 2013). Emotional rewards included the satisfaction of seeing children progress and develop. As in Moyles's (2001) research, interviewees referred to their 'passion' for working with children, which implies high levels of intrinsic motivation amongst interviewees. For a few of the interviewees, external validation in the form of positive feedback from family or colleagues about 'being good with children', or encouragement from tutors, had been pivotal in their decision to forge a career in the early years phase.

Participants felt that being a teacher would bring better pay, conditions and enhanced status, as Lloyd and Hallet's (2010) EYPS participants felt about their award. This raises the issue of how the interviewees conceptualised teaching as different to other roles working with young children in early years settings.

Professional knowledge was seen as a fundamental to teaching and professional practice, including: understanding how child learn and how to progress learning, 
preparing children for formal schooling at Key Stage 1; understanding phonics and pedagogical theory. Their in-depth knowledge of child development marked out early years teachers as different to other teachers. Teachers also needed to be able to reflect on and improve their practice.

Placements in settings had facilitated the development of practical teaching skills such as planning and conducting observations, and mentoring on placements had helped build participants' confidence. There was a clear understanding of the pastoral dimension of teaching, respondents spoke of the importance of understanding children's needs, and being an advocate for children.

Qualified Teacher Status was seen as significant in relation to professional practice. As one participant put it, they had considered a PGCE in Primary Education: 'Just to get this QTS tag, but I only wanted to work with (age) five to six, that's it'.

Yet five of them mistakenly thought that the EYTS programme conferred QTS, until they had actually started the course, although the course materials clearly indicated this was not the case. Despite this they completed the programme. This confusion could be symptomatic of wider confusion about the difference between EYTS, and the status of teachers in the primary sector. Nutbrown's (2013) response to More Great Childcare refers to similar misconceptions she encountered from practitioners, who had assumed the award of EYTS would offer parity with other teachers, in terms of pay, conditions and status.

Across all age groups and both genders, the interviewees were aware of the connection between higher level qualifications and the professionalisation of the sector, and undertaking the EYTS was a key part of their professional pride, and a way to improve their career prospects: 'With this qualification I can get a better position in a nursery' and 'Wanted to get a qualification- certified to make a difference' which demonstrates a belief that holding this professional qualification also confers a sense of having permission to bring about change and is reminiscent of 'credentialism'.

Many of our interviewees were already leading teams within early years settings, or aimed to do so. Gaining or improving leadership skills were seen as a key part of the EYTS programme, for some it was part of their motivation to undertake EYTS. Indeed leadership was viewed as a key aspect of the role of early years teachers in Nutbrown (2012) recommendations to government. For the interviewees, leadership skills were associated with professionalism and driving through change in settings, for some also about encouraging the professional development of colleagues.

As with the participants in Lloyd and Hallet's (2010) and Brock's (2013) research with EYPs discussed earlier, it was common for the respondents to associate the role of an early years professional with the possession of attributes and skills that facilitate interpersonal relationships. The focus on collaborative working could account for good communication skills being the most frequently mentioned personal attribute. Other desirable personal attributes were: patience, being able to take on board suggestions, and share ones own experience, being confident, 
enthusiastic, creative, motivated and caring. Principles were less often discussed in relation to professionalism, but when they were they were about inclusion, ethical practice and commitment to high standards of practice.

The interviewees saw being professional as part of a process, necessitating keeping up with academic reading and committing to continuing professional development, which clearly conforms to the discourse of New Professionalism discussed earlier. With regard to aspects of professionalism specifically related to working with children, there was an emphasis on the child-centred practice referred to by Fumato, Hargreaves, and Maxwell (2004).

The main barrier to professionalising the early years workforce was seen as the low levels of pay. In the longer term, this could determine whether practitioners who have chosen to take higher level qualifications will decide to remain in early years or move into the primary phase, where pay and conditions are better. As one interviewee put it: 'I can't even stay at this level because I've seen the pay and it's not as good'.

\section{Perceptions of the early years sector}

Amongst the interviewees, the early years are seen as a unique phase of education and their work underpins children's learning in later years, as one said:'being at the primary school taught me that the early years is so important and that everything we do supports what they do in Year 1'.

Participants took pride in the uniqueness of the early years phase, although alongside this was a sense that others outside of the field did not value and appreciate what they did, indicating that public understanding of early education has not increased since Brock's (2013) research.

Having graduates and qualified teachers working in the sector was seen as the current direction of travel in early years and essential to improving the education of young children. High-quality early years education was frequently linked to graduate level practitioners: 'A teacher's status in the early years- the way things are moving forward in early years- having degree level people working in early years. Making sure children have a good education at an early start.'

'I could have done an NVQ L2 but liked the idea of graduates teaching children, I have observed the difference in quality in terms of graduate and non-graduate'

There was a sense of separation between themselves as highly qualified professionals pursuing a career, and 'Unqualified teenagers' or practitioners working in early years because for them it was an 'easy option'. In contrast to their own passion for their work, it was noted by a few that there was a lack of passion in the current workforce, as one noted'Staff not having enough knowledge not passionate about work- think its easy money and doing second jobs in things they want to do.'This also suggests a frustration amongst the interviewees at the current level of commitment and expertise with in the ECEC workforce which does not bode well for working relations in settings. 


\section{A field in flux-changes in the early years sector}

As already indicated, there was a tension between the interviewees' aspirations for themselves as professionals and their perceptions of other practitioners in the early years sector. The theme of changes in the sector came through strongly in the interviews, and this could be how this tension is resolved, in that interviewees saw the sector in the process of much needed reformation, and for many of them, their position as the vanguard of this change was appealing. The interviewees in our sample did not seem critical about changes in the sector, and did not speak about holding onto or valuing established practice.

The majority of the interviewees wanted to improve practice by: bringing in new ideas, encouraging other practitioners to learn, delivering training for others in settings, and being a role model. In terms of changes they wanted to see amongst existing staff in settings, these focused on training and raising the level of qualifications. One interviewee expressed particularly strong views about training:

If I manage a nursery l'd make sure that the lot of them go for more training. They should know that children learn at every stage e.g. when babies- the nursery is not a place to drop children so that their parents can work. Nursery is a place a proper school.

This is an endorsement of the professionalisation agenda and demonstrates a belief in the virtues of professional training. It also fits with the discourse of NP, with its emphasis on standardising the education and training of the workforce.

The emphasis is clearly on children's education rather than their care, and resonates with Lloyd and Hallet's (2010) claim that early years policy in England has tended towards preparing children for school rather than a social pedagogical approach, which is more concerned with children's overall development

Several interviewees spoke about resistance to change amongst other staff in settings, and a preference for long established practices, for example: 'I think one of the problems, people tend to do what they have done, change is needed, but all opportunities for change do not happen.' One interviewee expressed disappointment that her ideas were not listened to: 'even though you have EYTS or degree'. This indicates a feeling that her educational status conferred value on her opinions and this should be appreciated within the setting, but is also an example of the positioning referred to by Simpson (2010) where practitioners are prevented from actualising their leadership role and enacting their professionalism.

\section{Conclusion}

This article reports the findings from a small-scale study of the views of newly qualified early years teachers. Although it is not possible to generalise from our sample to the wider population of new early years teachers, the study has merit as one of the first articles to report on this qualification, and the findings demonstrate patterns of response worthy of further research. 
The professionalisation of the early years sector has been a strong theme in policy, both nationally and internationally for the last 20 years (Kendall et al. 2012). Given the tsunami of changes that have swept through the field, it is worth speculating when the early years sector will be considered to be sufficiently professionalised.

Professionalisation in this context has largely meant raising the level of qualifications of practitioners in the field, and linking the push towards a graduate led workforce with the belief that this will enhance the quality of provision, despite the contested nature of what constitutes quality in education and training. In England, the professionalisation agenda for early years sits firmly within the discourse of New Professionalism and has been handed down from government rather than being led by a movement from within the sector (Hammond et al. 2015). It is evident that this new cadre of early years teachers are committed to, and see themselves as part of, the professionalisation of the workforce and do not view the this agenda as problematic but rather as necessary. They seem unaware of the potential of this process to enhance state control of the sector.

It is that NP could benefit the early years workforce, if it results in a wider recognition of the value of early years education and care. However, if the sector follows the historical pattern identified by Evetts (2014), as professionalisation has been imposed and regulated from without, then it is more likely to become a mode of occupational change and government control rather than bestowing practitioner autonomy and power. As the EYTS award has not been given parity with QTS in terms of pay and conditions, it appears that the 'appeal to professionalism' for the sector has been selective at best, and manipulative and dishonest at worst.

As Barron (2016) points out, the professional identity of this new group of early years teachers is still under construction, and our participants are taking up their careers in a sector of varied provision, much of it privately owned, where market forces cannot be disregarded.

The data show that, like the EYPs before them, our research participants are passionate about working with young children, knowledgeable about child development and learning, and aware of the expectations on them to lead practice and drive change in the sector. This passion has led them to work in the early years and a belief in the value of postgraduate, specialist training led them to the EYTS programme. It also demonstrates the seductive appeal of a discourse of professionalism that includes the promise of public service (Evetts 2014) and making a positive difference in the lives of children.

Working in the early years sector gives the participants a sense of pride, due to the uniqueness of this phase of education and the role it plays as a foundation for later learning. They see themselves as having acquired a body of professional knowledge, and the leadership skills that will enable them to bring about change in the sector. Yet they also prize the emotional qualities and attributes they see as inherent to being an early years teacher and find working with young children hugely rewarding. 
It is clear that there was a perception of difference between themselves and other less-qualified practitioners and a belief that many current staff in settings would benefit from further training. It will be important to observe how this translates into relationships between staff in settings and whether it impacts on successful teamwork. Time will tell if these new EYTs will be able to fully actualise their intended roles, or if resistance from colleagues in the sector will prevent this (Simpson 2010). Further research is necessary to evaluate the impact of the new EYTs on the sector and to ascertain if they become the 'agents of change' that they hope to be.

The interviewees are also aware of the low status accorded to their profession, and are dissatisfied with the low levels of pay. It remains to be seen how many of them will be tempted by better pay and conditions to become reception class teachers in schools or to take conversion courses to achieve QTS. Recent research by Osgood et al. (2017) also found that the lack of parity with QTS was a source of anger and frustration for the sector. In addition recruitment to EYTS training courses has fallen recently, and several providers have ceased to offer the award (Crown 2016). The existence of this initiative could be as brief as that of EYPs, only to be superseded by yet another form of professionalism within the early years sector.

\section{Disclosure statement}

No potential conflict of interest was reported by the authors.

\section{References}

Attride-Stirling, J. 2001. “Thematic Networks: An Analytic Tool for Qualitative Research." Qualitative Research 1 (3): 385-405.

Barron, I. 2016. "Flight Turbulence: The Stormy Professional Trajectory of Trainee Early Years' Teachers in England." International Journal of Early Years Education 24 (3) 325-341. doi:10.10 80/09669760.2016.1204906

Braun, V., and V. Clarke. 2006. "Using Thematic Analysis in Psychology." Qualitative Research in Psychology 3 (2): 77-101.

Brock, A. 2013. "Building a Model of Early Years Professionalism from Practitioners' Perspectives." Journal of Early Childhood Research 11 (1): 27-44.

Cameron, C., A. Mooney, and P. Moss. 2002. "The Child Care Workforce: Current Conditions and Future Directions." Critical Social Policy 22 (4): 572-595.

Campbell-Barr, V., and C. Leeson. 2016. Quality and Leadership in the Early Years. London: Sage.

Children's Workforce Development Council. 2008. Introduction and Information Guide: Early Years Professionals Creating Brighter Futures. London: CWDC.

Connell, R. 2013. "The Neoliberal Cascade and Education: An Essay on the Market Agenda and Its Consequences." Critical Studies in Education 54 (2): 99-112.

Crown, H. 2016. Providers Cut EYT Courses due to Low Demand. Nursery World 02 May 2016. Accessed November 26, 2017. https://www.nurseryworld.co.uk/nursery-world/news/1157040/ providers-cut-eyt-courses-due-to-low-demand

Davis, G., and A. Barry. 2013. "Positive Outcomes for Children: Early Years Professionals Effecting Change." Early Child Development and Care 183 (1): 37-48. 
Department for Education. 2013. More Great Childcare. Accessed November 02, 2016. www. education.gov.uk/publications

Evans, L. 2008. "Professionalism, Professionality and the Development of Education Professionals." British Journal of Education Studies 56 (1): 20-38.

Evetts, J. 2014. "The Concept of Professionalism: Professional Work, Professional Practice and Learning." In International Handbook of Research in Professional and Practice-Based Learning, edited by S. Billett, C. Harteis, and H. Gruber, 29-56. Springer International Handbooks of Education. Dordrecht: Springer.

Faulkner, D., and E. A. Coates. 2013. “Early Childhood Policy and Practice in England:Twenty Years of Change." International Journal of Early Years Education 21 (2-3): 244-263.

Fumato, H., D. Hargreaves, and S. Maxwell. 2004. "The Concept of Teaching; A Reappraisal." Early Years 24 (2): 179-191.

Gourd, J. 2013. "Up-Skilling the Workforce: Managing Change in Practice." In Early Years Policy: The Impact on Practice, edited by Z. Kingdon and J. Gourd, 117-134. Abingdon: Routledge.

Hallet, E. 2013. "'We All Share a Common Vision and Passion': Early Years Professionals Reflect upon their Leadership of Practice Role." Journal of Early Childhood Research 11 (3): 312-325.

Hammond, S., S. Powell, and K. Smith. 2015. "Towards Mentoring as Feminist Praxis in Early Childhood Education and Care in England." Early Years 35 (2): 139-153.

Hargreaves, L., and B. Hopper. 2006. “Early Years, Low Status? Early Years Teachers' Perceptions of their Occupational Status." Early Years 26 (2): 171-186.

Kendall, A., D. Carey, A. Cramp, and H. Perkins. 2012. "Barriers and Solutions to HE Progression for Early Years' Practitioners." Journal of Vocational Education and Training 64 (4): 543-560.

Lloyd, E., and E. Hallet. 2010. “Professionalising the Early Childhood Workforce in England: Work in Progress or Missed Opportunity?" Contemporary Issues in Early Childhood 11 (1): 75-88.

McClellend, C. E. 1990. “Escape from freedom? Reflections on German professionalization 18701933." In The formation of professions: Knowledge, state and strategy, edited by M. Burrage, and R. Torstendahl, 97-113. London: Sage.

Miller, L., and C. Cameron. 2014. International Perspectives in the Early Years. London: Sage Publications.

Moyles, J. 2001. “Passion, Paradox and Professionalism in Early Years Education." Early Years: An International Journal of Research and Development 21 (2): 81-95.

Murray, J. 2009. "The poor professionals". Education Guardian, 28 April.

Nutbrown, C. 2012. Foundations for Quality: The Independent Review of Early Education and Childcare Qualifications. Final Report. London: DFE.

Nutbrown, C. 2013. "Shaking the Foundations of Quality? Why 'Childcare' Policy Must Not Lead to Poor-Quality Early Education and Care." Sheffield: University of Sheffield. http://www.shef. ac.uk/polopoly_fs/1.263201

Ofsted. 2015. Early Years Inspection Handbook: Handbook for Inspecting Early Years in England Under Sections 49 and 50 of the Childcare Act 2006. London: Ofsted.

Osgood, J. 2006. "Deconstructing Professionalism in Early Childhood Education: Resisting the Regulatory Gaze." Contemporary Issues in Early Childhood 7 (1): 5-14.

Osgood, J., A. Elwick, L. Robertson, M. Sakr and D. Wilson. 2017. Early Years Teacher and Early Years Educator: A Scoping Study of the Impact, Experiences and Associated Issues of Recent Early Years Qualifications and Training in England. http://tactyc.org.uk/research/.

Peeters, J., and M. Vandenbroeck. 2011. "Childcare Practitioners and the Process of Professionalization." In Professionalization, Leadership and Management in the Early Years, edited by L. Miller and C. Cable, 62-76. London: Sage.

Simpson, D. 2010. "Becoming Professional? Exploring Early Years Professional Status and Its Implications for Workforce Reform in England." Journal of Early Childhood Research 8 (3): 269-281. 
Siraj-Blatchford, I., K. Sylva, S. Muttock, R. Gilden, and D. Bell. 2002. Researching Effective Pedagogy in the Early Years. Nottingham: DfES.

Storey, A. 2009. “How Fares the 'New Professionalism' in Schools? Findings from the 'State of the Nation' Project." Curriculum Journal 20 (2): 121-138.

Sylva, K., E. Melhuish, P. Sammons, I. Siraj-Blatchford, B. Taggart, R. Smees, A. Dobson, et al. 2004. The Effective Provision of Pre-School Education (EPPE) Project. Nottingham: DfES.

Sylva, K., E. Melhuish, P. Sammons, I. Siraj-Blatchford, and B. Taggart. 2014. Effective Preschool, Primary and Secondary Education 3-16 Project (EPPSE 3-16): Students' Educational and Developmental Outcomes at Age 16. Nottingham. DfE. RR354.

Urban, M. 2008. “Dealing with Uncertainty: Challenges and Possibilities for the Early Childhood Profession." European Early Childhood Education Research Journal. 16 (2): 135-152.

Urban, M. 2010. "Rethinking Professionalism in Early Childhood: Untested Feasibilities and Critical Ecologies." Contemporary Issues in Early Childhood 11 (1): 1-7.

Walker, M., J. Jeffes, R. Hart, P. Lord, and K. Kinder. 2011. Making the Links between Teachers' Professional Standards, Induction, Performance Management and Continuing Professional Development RR075. London: Department for Education.

Whalley, M. 2008. Leading Practice in Early Years Settings. Exeter: Learning Matters. 